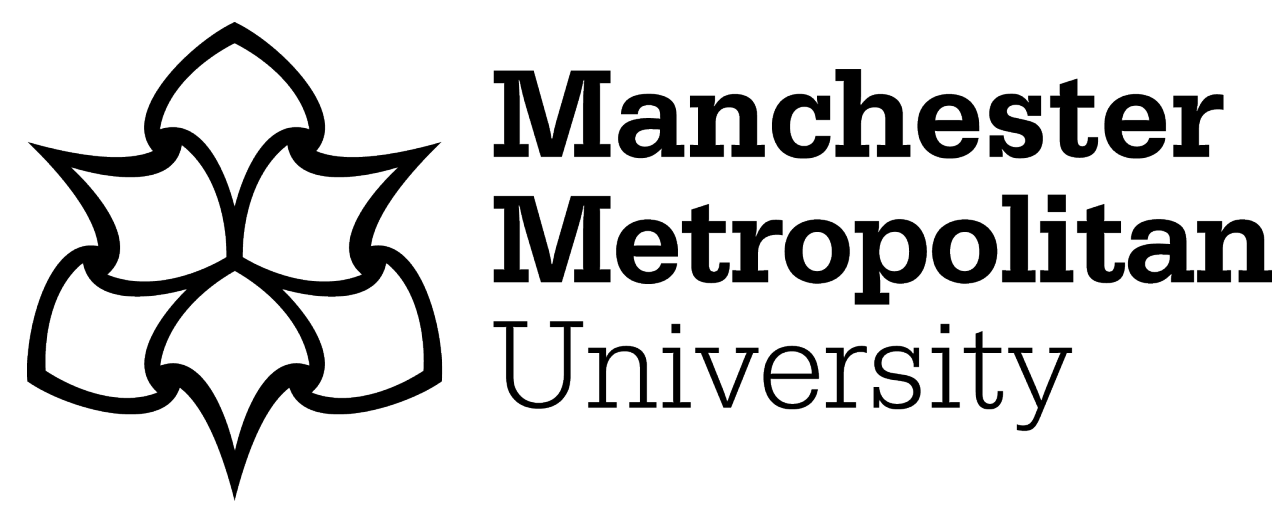

Hutchinson, Phil (2013) Relativism and the Social Sciences: From the SapirWhorf Hypothesis to Peter Winch. In: Encyclopedia of Philosophy and the Social Sciences. SAGE Publications, Inc.. ISBN 9781452276052

Downloaded from: https://e-space.mmu.ac.uk/628930/

Publisher: SAGE Publications, Inc.

DOI: https://doi.org/10.4135/9781452276052.n308

Please cite the published version 


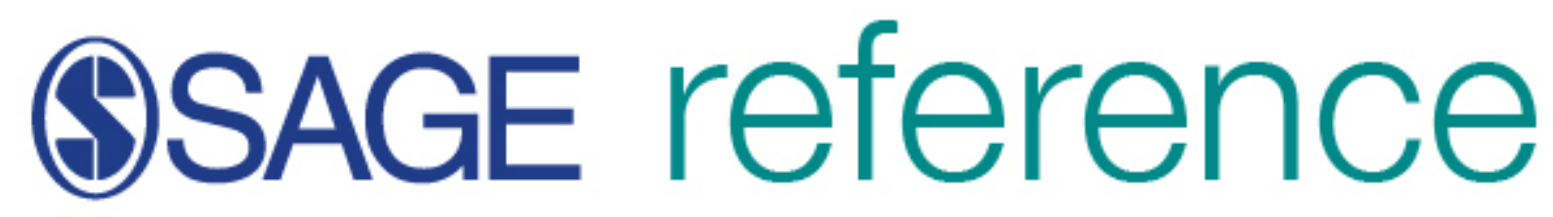

\section{Encyclopedia of Philosophy and the Social Sciences}

\section{Relativism and the Social Sciences: From the Sapir- Whorf Hypothesis to Peter Winch}

Contributors: Phil Hutchinson

Edited by: Byron Kaldis

Book Title: Encyclopedia of Philosophy and the Social Sciences

Chapter Title: "Relativism and the Social Sciences: From the Sapir-Whorf Hypothesis to Peter Winch"

Pub. Date: 2013

Access Date: March 4, 2020

Publishing Company: SAGE Publications, Inc.

City: Thousand Oaks

Print ISBN: 9781412986892

Online ISBN: 9781452276052

DOI: http://dx.doi.org/10.4135/9781452276052.n308

Print pages: 806-808

(C) 2013 SAGE Publications, Inc. All Rights Reserved.

This PDF has been generated from SAGE Knowledge. Please note that the pagination of the online version will vary from the pagination of the print book. 
Linguistic or conceptual relativity has been associated with certain theses in the philosophy of social sciences, playing a key role, in particular, in earlier philosophical and methodological discussions of social and cultural anthropology. This kind of linguistic or cognitive relativism and, in general, the relation between language and thought or between linguistic terms and conceptual categories, which was seen as indispensable to social inquiry by antipositivist or antiscientist circles in the philosophy of social sciences, has also been associated with specific readings of Ludwig Wittgenstein's language-games and forms of life.

This entry critically reviews two major instances of this alleged linguistic/conceptual relativism and dispels the resultant erroneous assumptions about relativism in the social sciences that were once dominant in the philosophy of social sciences.

\section{Origins}

It is widely assumed that the mid 20th century saw the emergence of two powerful relativist theories that posed a significant threat to the prospects of the social sciences. This assumption underpins the further widely held assumption that these challenges have been rebutted. These assumptions are only half true.

One of the two theories in question was advanced by the American linguist Benjamin Whorf (1897-1941), building on the work of his teacher, the anthropologist-linguist Edward Sapir, and this theory is usually referred to as the Sapir-Whorf hypothesis. The second figure often identified as having advanced a relativist theory is the British philosopher Peter Winch (1926-1997), in his book The Idea of a Social Science and Its Relation to Philosophy (hereafter, ISS), a book that is informed by the approach to philosophy pioneered by Wittgenstein. While Whorf avowedly advanced a theory of linguistic relativism, Winch sought to advance no theses, and, moreover, his writings neither propound nor endorse relativism.

In the following sections, we will first look at the Sapir-Whorf hypothesis and assess some criticisms of that theory. We will then progress to Winch's writings, clarifying his claims about the nature of social studies. We will see that far from endorsing or providing a variant of Whorf's thesis, Winch actually provides one with the resources for a critique of Whorf.

\section{The Sapir-Whorf Hypothesis and Linguistic Relativism}

Whorf's theory of linguistic relativism is founded on his claim that speakers of different natural languages, or more precisely natural languages belonging to different families, operate according to different grammatical rules and that these different grammars shape the thoughts of the native speakers of that language. What follows from such a claim is that the same physical evidence does not necessarily force upon a perceiver the same picture of the universe, for the picture is formed by the grammar of the language. Therefore, different languages are said to entail different pictures of the universe irrespective of those pictures' basis in the same physical data. Grammar, for Whorf, is the "shaper of ideas" and that which provides "thought materials." Therefore, Whorf hypothesizes that the nature of reality is relative to the grammar of a natural language.

While Whorf's theory has been subjected to a number of criticisms, some miss their target by misunderstanding the precise nature of the theory. For example, some took Whorf to be making a point about different vocabularies: for example, that language $A$ contains numerous words for phenomenon $X$, for which only one word exists in language $B$. This was not Whorf's claim and is of little interest to him. Others have criticized Whorf's foundational claim that different natural languages, particularly those belonging to different language families, such as Indo-European and non-Indo-European, have different grammars. This is challenged by those who subscribe to Noam Chomsky's linguistic theory, wherein Chomsky advances the theory of universal grammar. Such critics reject Whorf's relativism by contesting the grammatical pluralism on which his relativism is founded. If Chomsky's theory is true, then this does indeed seem to undermine Whorf's hypothesis. However, one 
does not have to subscribe to Chomsky's theory of generative grammar and its basis in a theory of an innate universal grammar to undermine Whorf's relativism. Indeed, one might even believe that one can defend Whorf's theory against a Chomskyan criticism by, for example, questioning the validity of Chomsky's theories. However, there is another, alternative, way to undermine Whorf's thesis without appealing to or subscribing to Chomsky's theories; here, Whorf's argument is identified as residing not in the claim that different grammars exist in different natural languages but rather in a set of unacknowledged philosophical assumptions that are operative in Whorf's hypothesis. This criticism of Whorf brings to the fore the philosophical assumptions underlying Whorf's claim that grammatical differences entail different metaphysics. In other words, rather than focusing on his grammatical pluralism, one might focus on Whorf's claim that one can read off a metaphysics from the grammar of a language. For one thing of note, all too often overlooked in discussions of Whorf's theory, is that his relativism is not entailed by his observations about the grammar of different languages; nor did Whorf claim it to be so. There is, rather, a philosophical argument operative in Whorf's thesis, which is assessable independently of his grammatical pluralism. A criticism addressed to this aspect of Whorf's thesis is one that seeks to show that Whorf's thesis lacks intelligibility. John W. Cook's critique is an exemplar of this approach.

On close examination, Whorf's claim that different metaphysics can be read off from different grammars can be shown to fall short of his aims, and this can be seen by examining his remarks about his own language: English. A little like the anthropologist who writes of the primitive superstitions of the tribe he is studying, while it remains literally unremarkable to him that he then prays before dinner and kisses a photograph of a loved one before going to sleep for the night, Whorf's writings about the metaphysics he claims to read off Hopi grammar are accompanied by a distinctly superficial depiction of the grammar of his own language. His arguments about grammatical categories determining the metaphysics of the speakers of the language are consequent on his being led astray by the surface grammar of his own language, because where Whorf took himself to be identifying a metaphysics that can be read off the grammar of English (and, when he turned to study that, Hopi), he was rather reading into English a metaphysics that owed much to his own preexisting, underlying metaphysical assumptions about English grammar. To paraphrase John W. Cook, Whorf was not reading off a metaphysics from the grammar of English but rather reading into English a metaphysics not there. For example, Whorf employs the example of the concept of "time" in support of his claim that metaphysics is read off grammar, but his assumptions about the metaphysics of time are simply read off his observation that in English "time" is a noun, and he seems to assume that nouns must correspond to something. Whorf is therefore being led astray by the surface (superficial) grammar of "time." When he then takes himself to have read off a metaphysics of time as being composed of "moments," "time slices," or "time flows," he is actually being led astray by his unacknowledged assumption that "time" as a noun in English must correspond to something.

To summarize, the real problem faced by someone who is persuaded by the Sapir-Whorf hypothesis is not that it is based on a now unfashionable theory of grammar, in light of the prominence attained by Chomsky's work. Rather, the real problem is that what had appeared to many (including Whorf) as a thesis founded upon, if not logically forced upon one by, the results of empirical studies of the grammar of natural languages is actually a set of claims emerging from the observer, such as Whorf, who is in the grip of an unacknowledged picture of grammar that leads him to first misrepresent his own language and then proceed to misrepresent those he is studying.

\section{Peter Winch and Relativism as One Consequence of Scientism}

It is widely assumed that Peter Winch, at least implicitly, endorsed some version of Whorf's theory in his ISS. It is also widely assumed that Winch propounded a theory of cultural relativism, based on his observations about grammar and rules. Both these assumptions are incorrect.

Winch claimed that social studies should be seen as philosophy. As he put the matter early in his book, where science is concerned with the explanation of particular real things and processes, the philosopher is con- 
cerned with the nature of reality in general—what counts as "real" or what we mean by "real." On this view, social studies are better understood as philosophy because their questions have central to them discussions about the meaning of that which is under study (e.g., "happiness," which has been the subject of much recent putatively empirical study). Specific normative questions such as "Should the state promote happiness through policy?" or questions demanding answers in the form of social facts such as "Is Britain happier than Norway?" or "Does socialism produce greater happiness than neoliberalism?" are parasitic upon the general question about the nature of happiness. The social scientist must concern herself with the question of what we take happiness to be or, put another way, what counts for us as happiness: Is it a psychological state, and if so, of what sort? Is it related to flourishing as a member of a species with a particular set of needs? Is a happy life necessarily a good life? Can happiness that is gained through the suffering of others be genuine happiness? Do we accept the drug addict's claim to be blissfully happy, following a fix, as genuine happiness? Is there a difference between genuine and subjective/apparent/false/synthetic happiness? And if there is, what are our grounds for saying so, and what are our criteria for "genuine happiness"? Are there degrees of happiness, and if so, how might these be measured? These are unavoidable questions, and they are questions that cannot be answered by empirical study or causal explanation. The point is that any attempt at empirical enquiry into happiness cannot bypass the philosophical discussion as to the general nature of happiness.

Winch's critique of certain assumptions in the social sciences is rich and multilayered; it has deep ethical dimensions that became increasingly prominent in his later post-ISS writings. Actions are meaningful, and their meaning is inextricably linked to the context and occasion of action. Believing that meaning can be understood through identification of an action's cause is to misunderstand the nature of action and meaning. So if one's conception of science demands that explanations are stated in the form of lawlike generalizations with predictive power, then that demands a noncontextual identification of act tokens, whereby the role of context in the meaning of an action (a specific act token) can be foregone. However, the nature of action is such that the context-the social situation-is intrinsic to its identity. Moreover, an attempt to deny or bypass the meaningful nature of action leads us to a misrepresentation of not only the actions of those whom the social scientist claims to be explaining but of ourselves too, for first and foremost the social scientist is an ordinary social actor. The act of understanding others involves understanding ourselves, and this is a point Winch increasingly sought to emphasize and one that might easily have been directed at Whorf. Failure to understand others through a misunderstanding of the meaningful nature of action results in failure to understand oneself in a manner that one might depict as bad faith. Furthermore, the observation that actions are meaningful leads to the recognition of them as open textured. Should one concede that lawlike generalizations might be possible for some general categories of action, it would still not be possible to rely on those generalizations having nonplatitudinous predictive worth because of their open texture.

\section{Conclusion}

In conclusion, Whorf sought to advance a relativist hypothesis, and we have seen that this emerged from his own underlying philosophical assumptions, which ultimately meant that he failed to achieve his goal. Winch was making specific observations about the nature of the questions and problems that are dealt with in social studies and how being in thrall to particular pictures of what counts as a valid form of explanation can impair our understanding of those questions and problems. For Winch, arguments for theories of cultural or linguistic relativism ultimately lack intelligibility, and they can usually be shown to emerge from a failure of self-understanding: a sort of bad faith or intellectual hubris. For Winch, relativism is usually a consequence of a subterranean scientism, and it is the tendency to the latter from which he sought to liberate his reader.

- grammar

- relativism

- metaphysics 
- Sapir-Whorf Hypothesis

- happiness

- linguistic theory

- philosophy and the social sciences

Phil Hutchinson

http://dx.doi.org/10.4135/9781452276052.n308

\section{See also}

- Causes Versus Reasons in Action Explanation

- Language and Society

- Language-Games and Forms of Life

- Relativisms and Their Ontologies

- Rule Following

- Social Anthropology

\section{Further Readings}

Cook, J. W. (1978a). Whorf's linguistic relativism I. Philosophical Investigations. 1(1), 1-30. http://dx.doi.org/ 10.1111/j.1467-9205.1978.tb00177.x

Cook, J. W. (1978b). Whorf's linguistic relativism II. Philosophical Investigations, 1(2), 1-37. http://dx.doi.org/ 10.1111/j.1467-9205.1978.tb00180.x

Hutchinson, P., Read, R., \& Sharrock, W. (2008). There is no such thing as a social science: In defence of Peter Winch. Farnham, England: Ashgate.

Lucy, J. A. (1992). Language diversity and thought: A reformulation of the linguistic relativity hypothesis. Cambridge, England: Cambridge University Press. http://dx.doi.org/10.1017/CBO9780511620843

Lucy, J. A. (1997). Linguistic relativity. Annual Review of Anthropology, 26, 291-312. http://dx.doi.org/ 10.1146/annurev.anthro.26.1.291

Pütz, M., \& Verspoor, M. (Eds.). (2000). Explorations in linguistic relativity. Amsterdam, Netherlands: John Benjamin.

Sapir, E. (1964). Conceptual categories in primitive languages. In D. H.Hymes (Ed.), Language in culture and society: A reader in linguistics and anthropology (p. 128). New York, NY: Harper \& Row. (Original work published 1931)

Whorf, B. L. (1956). Language, thought and reality: Selected writings (J. B.Carroll, Ed.). Cambridge: MIT Press.

Winch, P. (2008). The idea of a social science and its relation to philosophy. London, England: Routledge. (Original work published 1958; 2nd ed. 1990, with an introduction by R. Gaita) 